\title{
Mortars with Phase Change Materials: Contribute to Sustainable Construction
}

\author{
AGUIAR José ${ }^{1, a}$, CUNHA Sandra ${ }^{1, b}$ and KHERADMAND Mohammad ${ }^{1, c}$ \\ ${ }^{1}$ University of Minho, Campus de Azurém, 4800-058 Guimarães, Portugal \\ aaguiar@civil.uminho.pt, bsandracunha86@gmail.com, 'm.kheradmand@civi.uminho.pt
}

Keywords: Sustainable Construction, Phase Change Materials (PCM), Mortars.

\begin{abstract}
In a society with a high growth rate and increased standards of comfort arises the need to minimize the currently high energy consumption by taking advantage of renewable energy sources. The mortars with incorporation of phase change materials (PCM) have the ability to regulate the temperature inside buildings, contributing to the thermal comfort and reduction of the use of heating and cooling equipment, using only the energy supplied by the sun. This paper aims to contribute to the study of mortars incorporating PCM. The main characteristics of the material and the mortars doped with PCM, will be presented. It also aims to clarify the differences in the physical and mechanical characteristics of mortars doped with different types of PCM.
\end{abstract}

\section{Introduction}

Every year, the energy powered by the sun is about 10000 times higher than the actual energy consumption worldwide. Thus, the need to find a way to take advantage of this natural energy source is pressing [1].

Presently, the concerns related to the energy consumption of buildings are increasing. The largest part of the energy consumption in residential sector is associated with heating and cooling.

Therefore, it becomes imperative to obtain a constructive solution that minimizes these consumptions, improving the level of comfort inside buildings without damaging the environment. Furthermore, it is important to consider constructive solutions with renewable energy resources, providing an improvement in the quality of the buildings, especially in the comfort level of the occupants, without problems to the environment.

The incorporation of Phase Change Materials (PCM) in mortars for the interior appears as a possible solution in an attempt to solve, or at least minimize, the massive energetic consumption related with buildings. The use of this material allows the regulation of temperature inside buildings through latent heat thermal energy storage, using only solar energy as a resource, or at least reducing the need to use heating and cooling equipment.

Sustainable development is closely connected to three dimensions: economic, social and environmental. It is important to have a balance and harmony between them. The creation of a strong connection between the construction industry and the pillars of sustainable development is particularly important and early started to merit the attention of stakeholders in the construction sector.

The incorporation of PCM microcapsules in mortars brings social, economic and environmental benefits, demonstrating a significant contribution to a construction with a higher value of sustainability. The social benefits derive from the thermal comfort increase inside buildings, given that nowadays this is an important requirement and frequently demanded by buyers and potential sellers as an important decision parameter. The increase of thermal comfort is achieved by the thermal capacity of the PCM, allowing store and release of energy, keeping the interior temperature sensibly constant, or at least with less variation. The environmental aspect concerns the fossil fuels depletion, given that this technology aims at maintaining constant temperatures inside the building, consequently leading to a decrease on air conditioning equipment usage. The economic benefit is 
related to the technology adequacy and implementation costs. These should be supported and easily amortized by the user. It may also be noted that the economic benefits of reduced energy consumption and lag times for lower demand, are evident and can be achieved with the use of PCM.

A broad knowledge of the thermo-physical properties of PCM is necessary for the correct design/optimization approaches for their use in building constructions. In this way, one of the most important properties to determine is the temperature-enthalpy relationship.

\section{Phase Change Materials}

It is known that all materials interact with the environment. However most of them lack the capability to alter its own properties according to the environment characteristics in which they are applied.

Phase change materials (PCM) possess the capability to alter its own state as function of the environmental temperature (Fig. 1) [2]. In other words, when the surrounding environmental temperature of PCM increases until the materials fusion point, it suffers a change from a solid state to a liquid state, absorbing and storing the heat energy from the environment. On the other hand when the temperature decreases until the PCM solidification point, the material alters from the liquid state to solid state, releasing the previously stored energy to the environment. This application could be made in coating mortars of buildings, with advantage in the passive regulation of internal temperature with increase of thermal inertia [3].
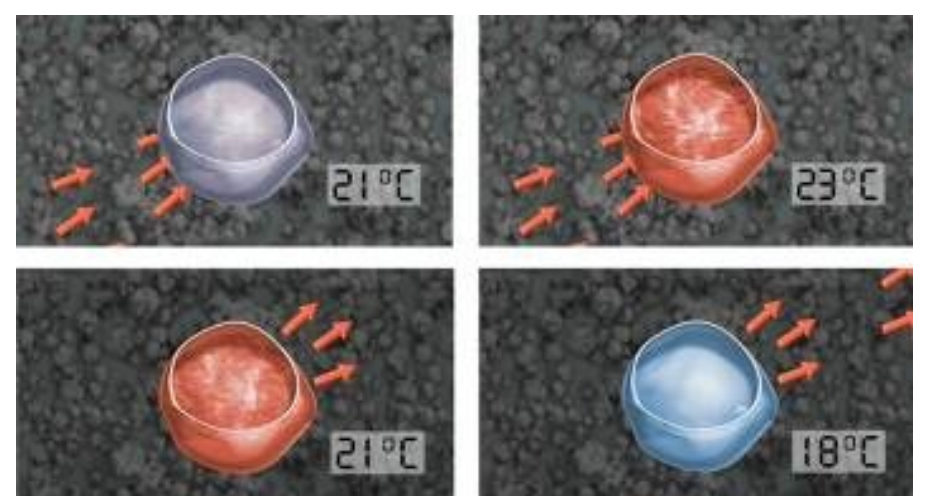

Fig. 1. Phase Change Processes [4].

Encapsulation. The PCM must be encapsulated, for its correct use, otherwise during the liquid phase there is a possibility that it moves from the original area of application.

There are two main forms of encapsulation, macroencapsulation (Fig. 2) and microencapsulation (Fig. 3). The macroencapsulation is based in the introduction of PCM into tubes, panels or other large containers. It is usually done in containers with more than $1 \mathrm{~cm}$ of diameter and presents a better compatibility with the material, improving the handling in construction [5]. The microencapsulation of phase change material consists on covering the material particles, with a material, usually a polymer, commonly known capsule, with dimensions between $1 \mu \mathrm{m}$ to $60 \mu \mathrm{m}$. The polymer used could be polymethylmethacrylate, polyuria or polyurethane and should respond at some demands of operation, as high heat transfer. The microcapsules can be spherical or asymmetric and with variable shape. The advantage of this encapsulation process is the improvement of heat transfer, through its large surface area $[5,6]$.

The phase change materials with phase transition from solid to liquid are preferred for the thermal energy storage, because the associated volume variation is lower than the associated to the transition from liquid to gaseous or from gaseous to solid $[7,8]$. 


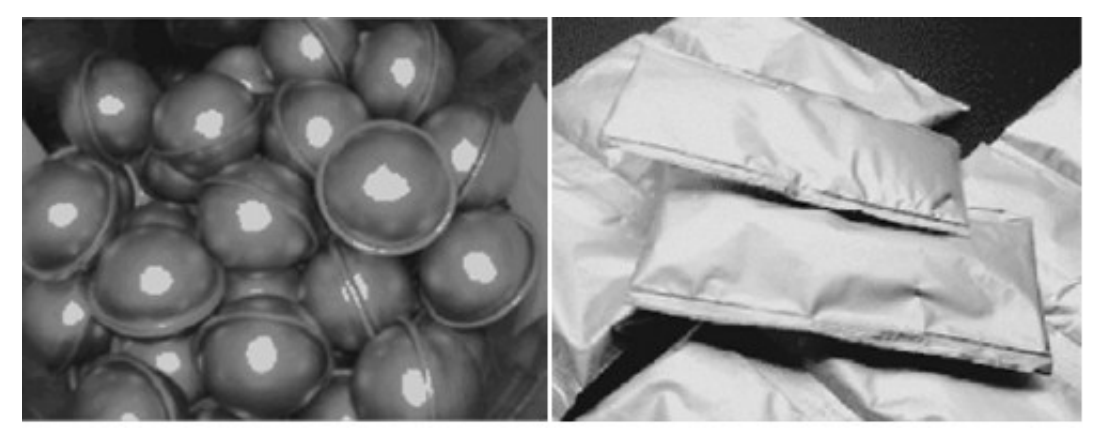

Fig. 2. Macroencapsulation [5].

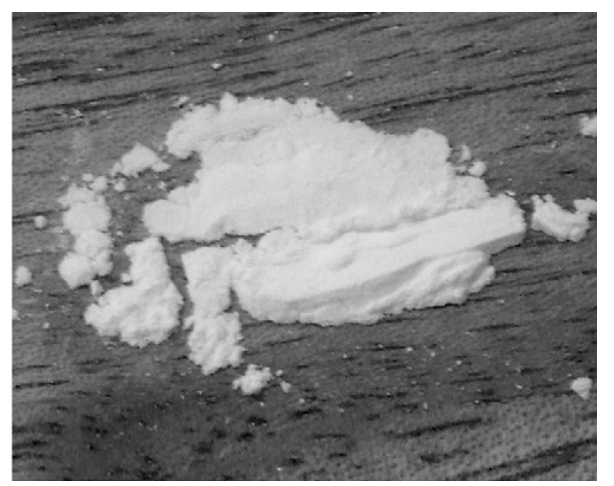

Fig. 3. Microencapsulation [3].

Classification. In 1983 emerged the first classification of substances used for thermal storage. These are classified as organic, inorganic and eutectic mixtures. Organic materials can be nonparaffinic or paraffinic. Usually, they have congruent phase changes without degradation. The inorganic materials are classified as hydrated salts and metals. The eutectic mixtures result from the combination of two or more compounds of organic and/or inorganic nature. By this way, it is possible to correspond to the need of more suitable transition temperatures for the demands [5, 9].

Properties. Not all existing PCM can be used for thermal storage. An ideal PCM must present certain thermo-physic, kinetic, chemical and economic properties. Thermo-physically, the transition temperature for the selected PCM must be within the desired range in order to guarantee both the storage and release of thermal energy. A high transition heat by volume unit is also required, in order to maximize the stored energy while minimizing the PCM usage, as well as a high sensitive heat (represented by its calorific capability), which allows an increase in its energy storing capability. Furthermore, high thermal conductivity characteristics in both solid and liquid states promote heat transfer with a reduced variation in volume during phase transition, reducing contention issues. From the kinetic point of view, a high growth velocity of the crystals can prevent sub cooling of the PCM liquid phase, enhancing its response to the surrounding demands. Thirdly, regarding the chemical properties, the chosen PCM should not be susceptible to degradation following a high number of cycles, while it must also be non-corrosive to construction materials, as well as non-flammable, non-toxic and non-explosive, in order to attend to environmental and security concerns. Finally, bearing in mind economic characteristics, availability and low acquisition cost are the main factors preceding the establishment of PCM as a competitive solution in comparison to conventional constructive and thermal storing systems [5].

Generally, the standard measurement method for the analysis of many thermo-physical properties is the Differential Scanning Calorimeter (DSC). From the literature survey [10-12] there are different possibilities of operation methods to analyze PCM through DSC testing. The two most common methods are: the dynamic method which corresponds to a constant heating rate and the step method which consists in applying variable heating rates to the sample [11]. Barreneche et al. [12] state that dynamic method and step method are suitable for the organic materials such as 
paraffin. The drawbacks of the step method are related to its programming complexity, the fact that it is time consuming and the difficulties in data treatment/interpretation [13].

Application in construction. Between all phase change materials possible applications in buildings, the most interesting is its incorporation in construction materials altering their materials thermal properties. The PCM may be used for thermal storage of passive solar heating being integrated in the floor, walls or ceilings, as well as being an integrating part of the most complex energetic system, such as heat pumps and solar panels [2].

The selection of the PCM transition temperature adequate to the atmospheric temperature is extremely important for the functionality of the solution. The adequacy of several PCM for incorporation in gypsum plasterboard was studied by Khudhairi et al [14]. Although the employed materials presented a great ability for energy storing capability, their transition temperature did not achieve the comfort band. This study shows the suitability of various PCM for incorporation into gypsum boards. However, despite having large thermal storage capacity, the used PCM was not placed in operation, because the transition temperature did not coincide with the range of comfort temperature.

PCM can be used in solutions for walls, floors and ceilings. Presently also exist some commercial solutions. The application of PCM in the walls of buildings is the preferential solution for exploring the potential of these materials. The incorporation of phase change materials in gypsum plasterboard has been the subject of several studies performed due to its low cost and various possibilities of application [15-18]. Darkwa et al., investigated the behavior of two solutions with incorporation of PCM in gypsum plasterboard. In one side the plasterboard used had $12 \mathrm{~mm}$ of thickness, all impregnated with PCM in order to compare with another situation in which they applied simple plasterboards with $10 \mathrm{~mm}$ of thickness, covered by PCM laminate with $2 \mathrm{~mm}$. The amount of PCM incorporated in both cases was the same. The results showed that the use of PCM laminate is more efficient since it contributed to an increase in the minimum temperature [17].

However, other solutions had also been developed like alveolar PVC panels with PCM macroencapsulated, blocks and bricks [5, 19]. Cabeza et al., constructed and monitored the behavior of concrete test cells, with and without addition of 5\% of PCM microcapsules. The incorporation of PCM was made in the concrete used on the roof and south and west walls. During the summer and without ventilation a decrease in maximum temperature and a time lag of about 2 hours were recorded [5].

The floors are probably one of the most important locals for heating and cooling a building. There are several authors who had investigated constructive solutions with incorporation of phase change materials, with applications in floors. These solutions are varied, such as electric heating under floor systems incorporating polyethylene plates impregnated with PCM, incorporation of PCM in concrete slab and the application of two types of PCM with different transition temperatures [9, 20-22].

The use of constructive solutions on ceilings ranges from the gypsum panels to steel panels with circulation of PCM in capillary networks $[23,24]$.

\section{Influence of the use of different PCM microcapsules}

The mortars with incorporation of phase change materials (PCM) have the ability to regulate the temperature inside buildings, contributing to the thermal comfort and reduction of the use of heating and cooling equipment, using only the energy supplied by the sun. However, the incorporation of phase change materials in mortars modifies its characteristics. Thus, the need to compare mortars doped with two kinds of PCM emerged.

Sixteen compositions were developed taking into account the future application of the mortar developed in the construction industry. 
The PCM content was fixed in $0 \%, 10 \%, 20 \%$ and $30 \%$ of total mass of solid particles. In order to overcome some of the problems related with the mortar shrinkage and consequent cracking, polyamide fibers and superplasticizer were incorporated.

Type of PCM microcapsules. Two different types of PCM microcapsules, designated as A and $\mathrm{B}$, were used. Both samples were used in powder form that means completely dry, although there is also the possibility of obtaining the same material in emulsion. In this study we decided to use the dry PCM in order to facilitate their incorporation in pre-mixed mortars.

The PCM microcapsules tests were performed in order to compare the PCM provided by two different producers. The microcapsules $\mathrm{A}$ are constituted by a wall in polymethylmethacrylate and a core in paraffin, with transition temperature of about $22.5{ }^{\circ} \mathrm{C}$ and enthalpy of $110 \mathrm{~kJ} / \mathrm{kg}$. The microcapsules of PCM A exhibit a transition temperature of $25^{\circ} \mathrm{C}$ in the heating cycle and $20^{\circ} \mathrm{C}$ in the cooling cycle. The microcapsules B are composed of a wall in melamine-formaldehyde and a core in paraffin, with temperature transition of about $22.5^{\circ} \mathrm{C}$ and enthalpy of $147.9 \mathrm{~kJ} / \mathrm{kg}$. These exhibit a transition temperature of $24^{\circ} \mathrm{C}$ in the heating cycle and $21{ }^{\circ} \mathrm{C}$ in the cooling cycle.

The tests conducted using the high resolution scanning electron microscope indicate that the polymer present in the microcapsules A is rougher (Fig. 4) compared to the polymer used in the microcapsules B (Fig. 5) that presents a more regular texture.

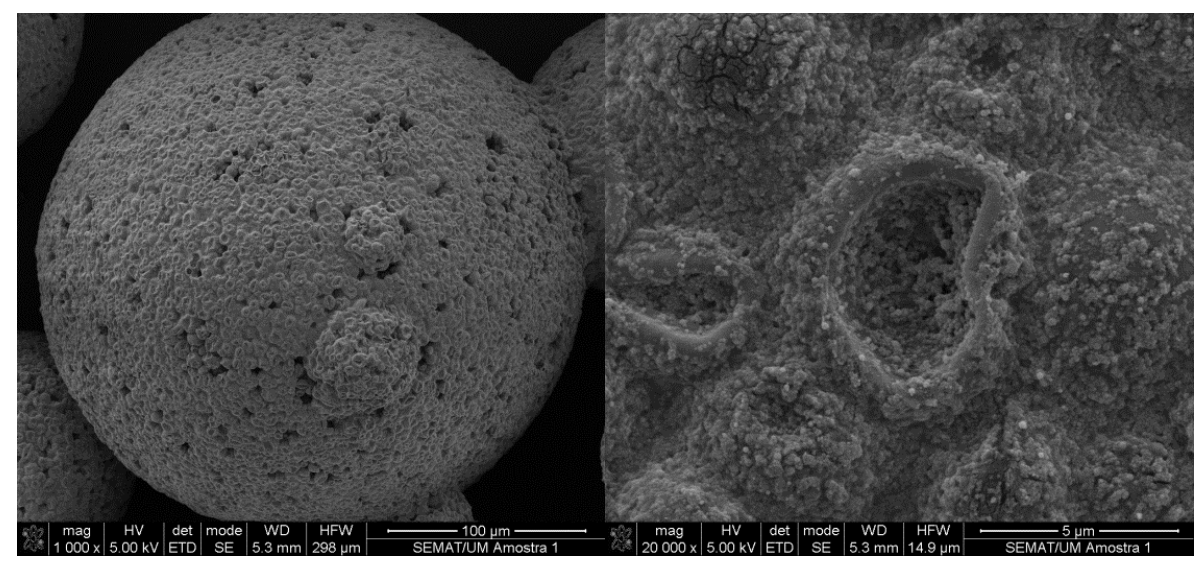

a)

b)

Fig. 4. Microscope observation of polymer surface of the microcapsules A: a) Enlargement of 1000x, b) Enlargement of 20000x.

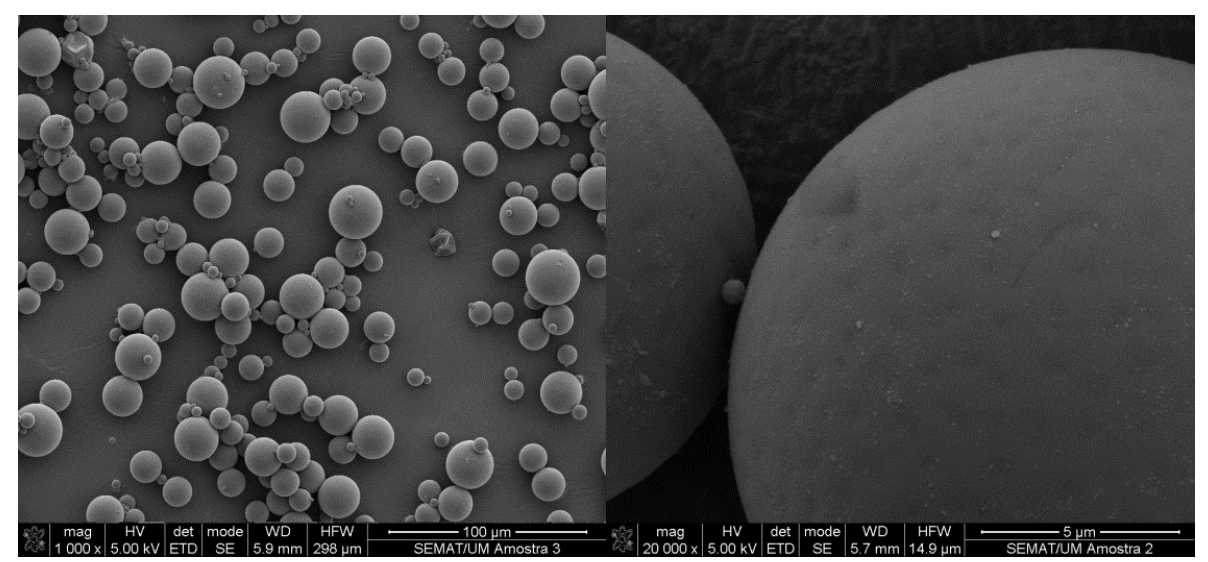

a)

b)

Fig. 5. Microscope observation of polymer surface of the microcapsules B: a) Enlargement of 1000x, b) Enlargement of 20000x.

With the purpose of obtain more information related with the dimensions of PCM microcapsules granulometry tests were performed, using a laser particle size analyzer. It was possible to observe that the microcapsules A are agglomerated, having a greater dimension when observed under the 
electron microscope. However, the agitation that the sample suffer during the laser particle size analyze, allows the dispersion of agglomerated microcapsules. In this way, it was possible to conclude that the microcapsules A have a particle size distribution between 5.8 to $219 \mu \mathrm{m}$ and an average particle size of $37.24 \mu \mathrm{m}$. The microcapsules B present a particle size distribution between 5.8 to $339 \mu \mathrm{m}$ and an average particle size of $43.91 \mu \mathrm{m}$ (Fig. 6).

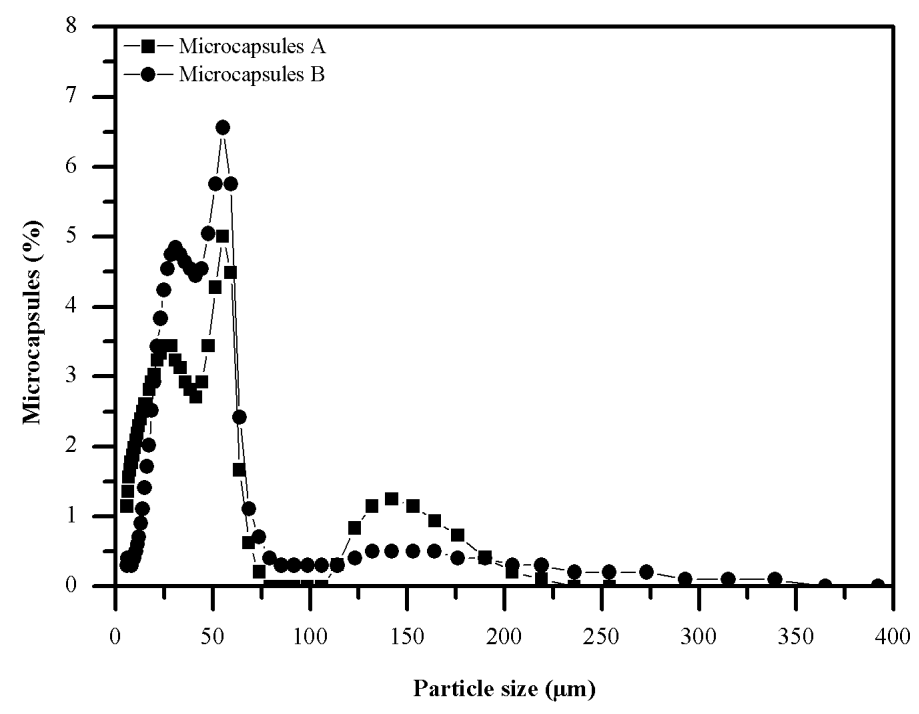

Fig. 6. Particle size distribution of PCM microcapsules.

Compositions. The studied compositions are presented in Table 1. The compositions present different contents of aerial lime, gypsum and PCM.

The experiments for thermal performance of mortars also involved the study of two mortars containing PCMs. The first mortar, here termed as SPCMM24, is a single PCM mortar that contains MC24. The second mortar, here termed as HPCMM18_28, involves the combined use of MC18 and MC28 in the same total quantity as the first mortar contain only MC24. Detailed information on the mix proportions and adopted materials are shown in Table 2.

Table 1. Composition of mortars (Microcapsules of PCM, superplasticizer, water and fibers as \% of total mass of solid particles; gypsum and sand as \% of binders mass).

\begin{tabular}{|c|c|c|c|c|c|c|}
\hline Compositions & Sand & $\begin{array}{c}\text { Microcapsules } \\
\text { of PCM A }\end{array}$ & $\begin{array}{c}\text { Microcapsules } \\
\text { of PCM B }\end{array}$ & Fibers & Gypsum & Superplasticizer \\
\hline L100G0 & 561.4 & 0.0 & 0.0 & 0.0 & 0.0 & 0.0 \\
\hline L90G10 & 561.4 & 0.0 & 0.0 & 0.0 & 10.0 & 0.0 \\
\hline L100G0PCM20-A & 561.4 & 20.0 & 0.0 & 0.1 & 0.0 & 1.0 \\
\hline L100G0PCM20F-A & 561.4 & 20.0 & 0.0 & 0.1 & 10.0 & 1.0 \\
\hline L90G10PCM10F-A & 561.4 & 10.0 & 0.0 & 0.1 & 10.0 & 1.0 \\
\hline L90G10PCM20F-A & 561.4 & 20.0 & 0.0 & 0.1 & 10.0 & 1.0 \\
\hline L90G10PCM30F-A & 561.4 & 30.0 & 0.0 & 0.1 & 10.0 & 1.0 \\
\hline L80G20PCM20F-A & 561.4 & 20.0 & 0.0 & 0.1 & 20.0 & 1.0 \\
\hline L60G40PCM20F-A & 561.4 & 20.0 & 0.0 & 0.1 & 40.0 & 1.0 \\
\hline L100G0PCM20-B & 561.4 & 0.0 & 20.0 & 0.0 & 0.0 & 1.0 \\
\hline L100G0PCM20F-B & 561.4 & 0.0 & 20.0 & 0.1 & 0.0 & 1.0 \\
\hline L90G10PCM10F-B & 561.4 & 0.0 & 10.0 & 0.1 & 10.0 & 1.0 \\
\hline L90G10PCM20F-B & 561.4 & 0.0 & 20.0 & 0.1 & 10.0 & 1.0 \\
\hline L90G10PCM30F-B & 561.4 & 0.0 & 30.0 & 0.1 & 10.0 & 1.0 \\
\hline L80G20PCM20F-B & 561.4 & 0.0 & 20.0 & 0.1 & 20.0 & 1.0 \\
\hline L60G40PCM20F-B & 561.4 & 0.0 & 20.0 & 0.1 & 40.0 & 1.0 \\
\hline
\end{tabular}


Table 2. Mix proportions of formulations SPCMM24 and HPCMM1828.

\begin{tabular}{|c|c|c|}
\hline \multirow{2}{*}{ Materials } & \multicolumn{2}{|c|}{ Formulations (percentage of the total weight of mortar) } \\
\cline { 2 - 3 } & SPCMM24 & HPCMM18_28 \\
\hline Cement type I class 42.5R & 31.32 & 31.32 \\
\hline Sand & 30.59 & 30.59 \\
\hline Water & 18.79 & 18.79 \\
\hline Super Plasticizer (water reducer) & 0.94 & 0.94 \\
\hline MC18 & - & 9.175 \\
\hline MC24 & 18.34 & - \\
\hline MC28 & - & 9.175 \\
\hline
\end{tabular}

Workability. The workability tests were performed with the main goal of verifying the adequacy for application of the developed mortars.

According to Fig. 7 it was possible to observe that the incorporation of $20 \%$ of the microcapsules A causes an increase in the amount of water of about $62 \%$. This situation can be explained by the reduced particle dimension of the used PCM and by the water absorption of the polymeric wall of the microcapsule. However, the incorporation of microcapsules B also causes an increase in the amount of water, but smaller, this being only about $12 \%$. This behavior can be explained by the use of capsules with a less rough surface and higher particle dimension.

The incorporation of fibers did not cause any change in the amount of water added to the mortar, however there was a slight reduction in the flow diameter obtained for the mortars with incorporation of microcapsules $\mathrm{A}$ and $\mathrm{B}$.
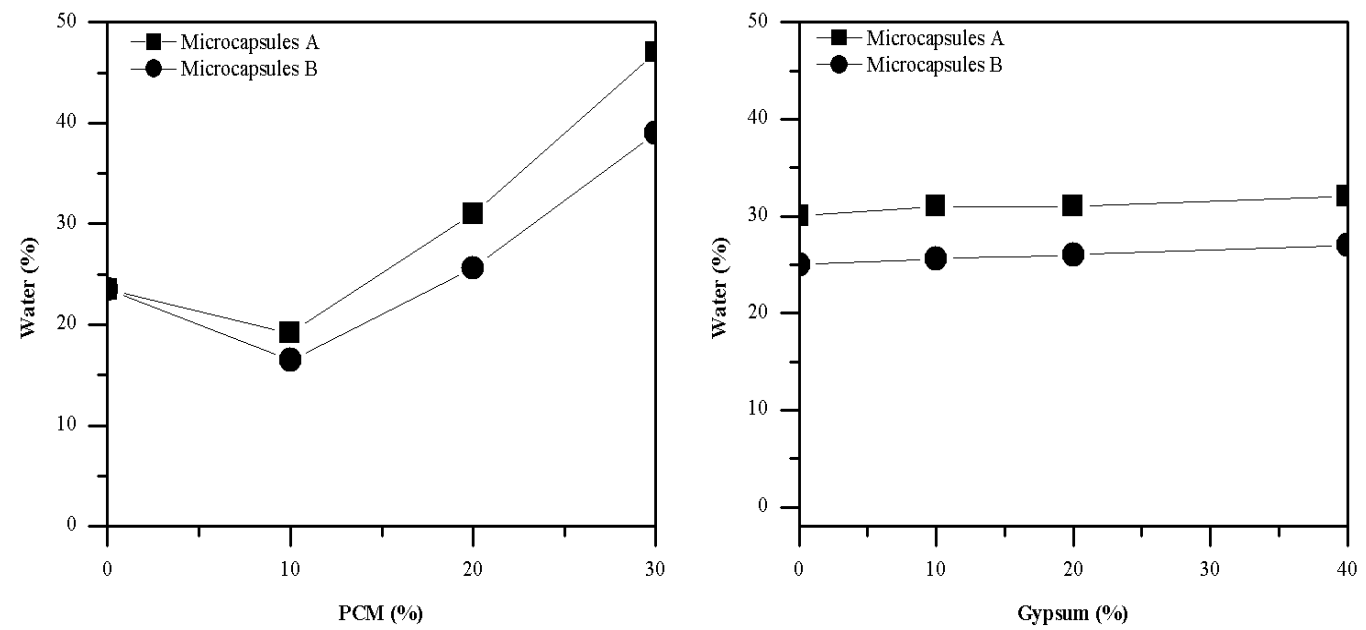

Fig. 7. Water added to the mortar (in $\%$ of total mass of solid particles).

Flexural and compressive behavior. According to the results (Fig. 8) it was possible to observe a significant improvement in mechanical properties caused by the introduction of microcapsules A. However, the improvement of mechanical characteristics caused by the incorporation of microcapsules B is lower.

The incorporation of $10 \%$ PCM leads to an increase in the value of flexural strength of about $380 \%$ and about $600 \%$ in compressive strength for the mortars with incorporation of microcapsules A. Regarding the mortars with incorporation of microcapsules $\mathrm{B}$, the increase is about $85 \%$ in flexural strength and about $130 \%$ in compressive strength. These values were obtained comparing compositions with $10 \%$ of PCM with the composition without PCM. This increase in mechanical strengths is related to the increase of porosity caused by the introduction of higher water content and PCM presence. The increase in porosity benefits the carbonation of mortars, which was more evident in mortars with incorporation of microcapsules $\mathrm{A}$, since the water content present is higher and the surface roughness of the PCM is higher for these mortars. However, it is possible to verify a 
decrease in the value of compressive and flexural strength with a PCM content of $30 \%$ when compared to the $20 \% \mathrm{PCM}$ composition. Therefore is possible to conclude that the optimal content of PCM in terms of mechanical properties corresponds to $20 \%$. Nonetheless, the value obtained for a PCM content of $30 \%$ is slightly higher or identical than the value presented by the mortar without PCM, which allows for the conclusion of the beneficial effect caused by the incorporation of PCM in mortars.
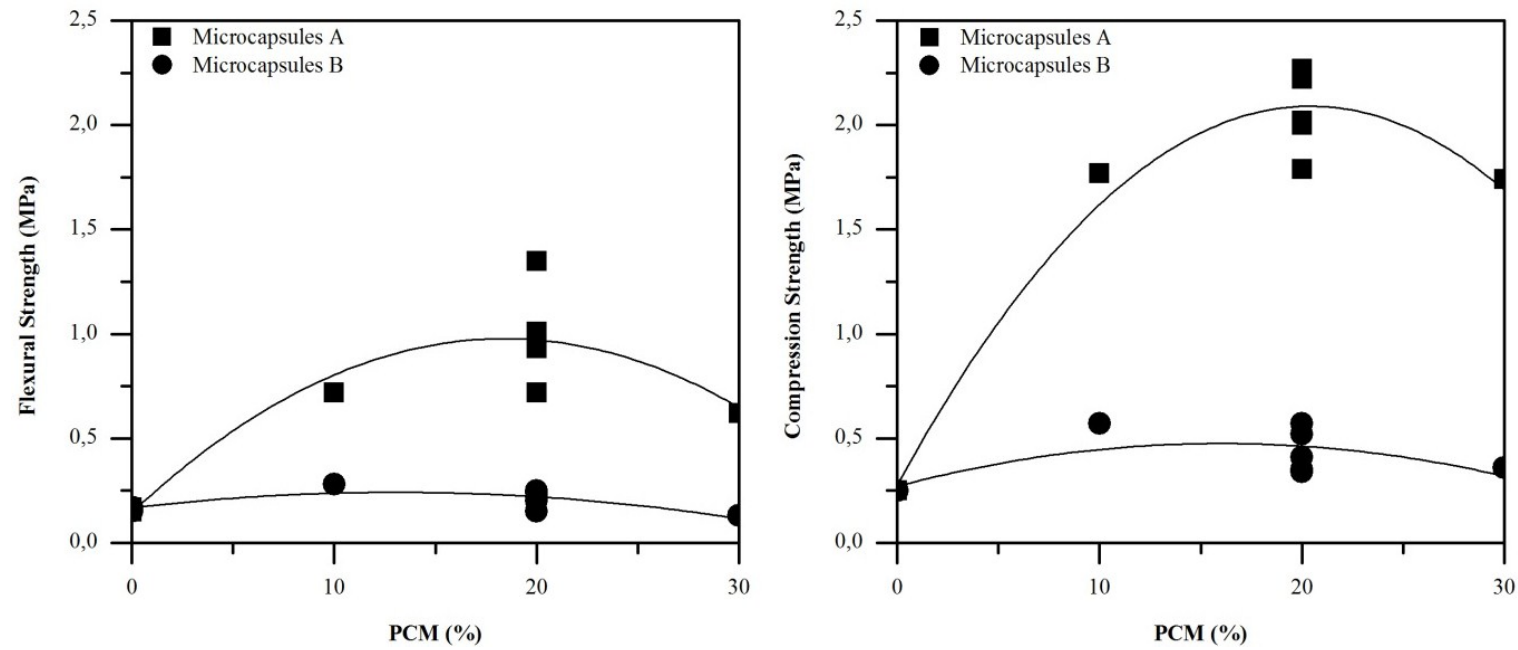

Fig. 8. Flexural and compressive behaviour.

Shrinkage. The shrinkage study was performed for only 9 of the 16 compositions studied. Thus, it was possible to observe the influence of the presence of PCM microcapsules in the mortars.

According to Fig. 9 it was possible to verify different behaviors in mortars with incorporation of the microcapsules A and B.
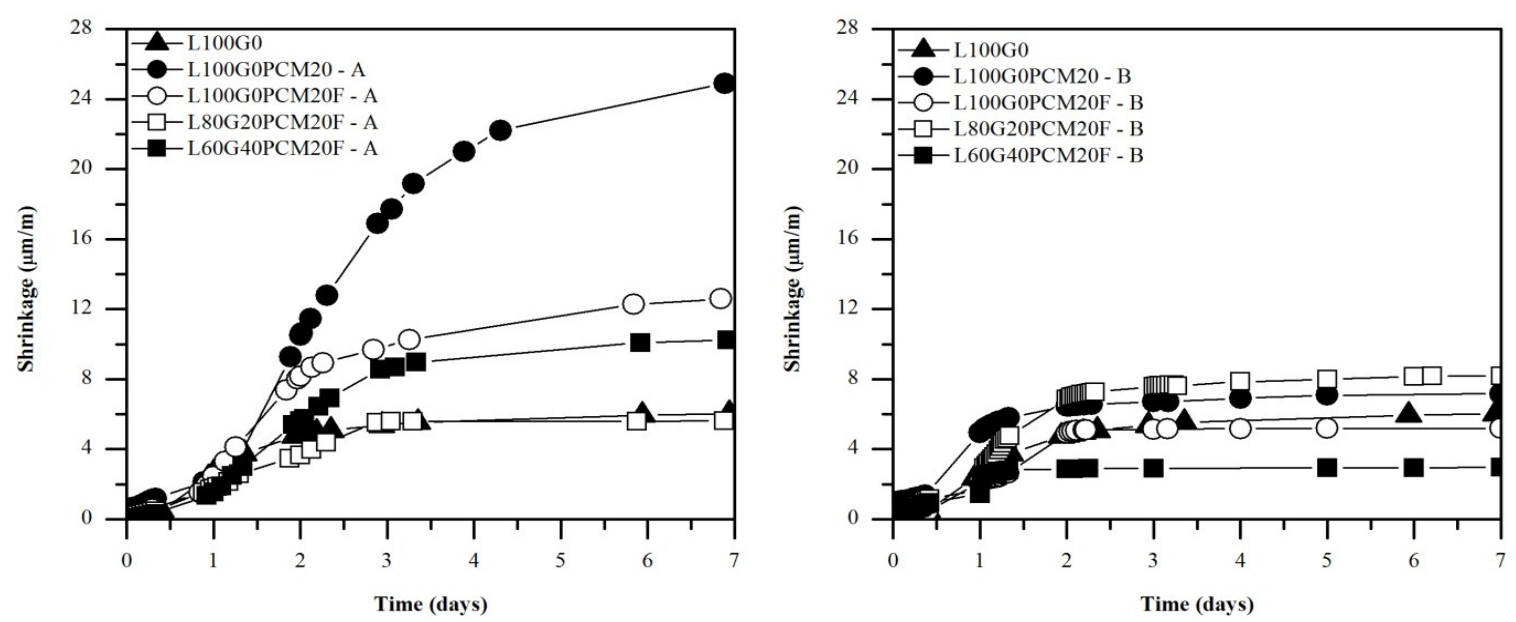

Fig. 9. Shrinkage values since moulding until 7 days.

The introduction of $20 \%$ of microcapsules A, causes an increase in shrinkage of about $300 \%$ compared to the reference mortar. The addition of polyamide fibers causes a decrease in shrinkage to about $50 \%$. With the addition of gypsum it was possible to observe a decrease in shrinkage. The addition of $40 \%$ gypsum allows a reduction in the shrinkage of about $40 \%$.

The introduction of $20 \%$ of microcapsules B causes an increase in shrinkage of about $20 \%$ compared to the reference mortar. The incorporation of polyamide fibers allows for the verification of a decrease of about $30 \%$. Finally the incorporation of $40 \%$ gypsum seems to cause a decrease in the value of shrinkage of about $40 \%$. 
The increase in shrinkage with the incorporation of PCM microcapsules is related to a greater amount of water used, while its reduction is caused by the inclusion of fibers, which are related to the prevention of dimension variations inside the mortar. Moreover, the reduction of shrinkage observed with the addition of gypsum, is connected to the expansion which occurs with its hydration.

The incorporation of $20 \%$ of microcapsules B, compared with the incorporation of $20 \%$ of microcapsules A, causes a decrease in shrinkage of about $70 \%$, which can be explained by the presence of lower water content in the mortars with incorporation of microcapsules B.

Thermal performance of mortars. The results for mortars incorporating the PCM microcapsules are shown in Table 3.

Table 3. PCM incorporated into mortar DSC enthalpy, onset and end temperatures for different plaster mortars.

\begin{tabular}{|l|c|c|c|c|c|c|c|c|c|}
\hline \multirow{2}{*}{ Designation } & \multirow{2}{*}{$\begin{array}{c}\text { Weight } \\
(\mathrm{mg})\end{array}$} & $\begin{array}{c}\text { Onset } \\
\text { temp. }(\mathrm{C})\end{array}$ & $\begin{array}{c}\text { End } \\
\text { Temp. } \\
(\mathrm{C})\end{array}$ & $\begin{array}{c}\text { Enthalpy } \\
(\mathrm{kJ} / \mathrm{kg})\end{array}$ & $\begin{array}{c}\text { Peak T } \\
(\mathrm{C})\end{array}$ & $\begin{array}{c}\text { Onset } \\
\text { temp.(s) } \\
(\mathrm{C})\end{array}$ & $\begin{array}{c}\text { End } \\
\text { temp. } \\
(\mathrm{C})\end{array}$ & $\begin{array}{c}\text { Enthalpy } \\
(\mathrm{kJ} / \mathrm{kg})\end{array}$ & $\begin{array}{c}\text { Peak T } \\
(\mathrm{C})\end{array}$ \\
\hline SPCMM24 & 10.0 & 17.77 & 23.61 & 29.76 & 22.56 & 22.79 & 16.79 & 25.08 & 21.77 \\
\hline HPCMM18_28 & 10.3 & 15.36, & 18.5, & 24.61, & 17.49, & 25.52, & 22.55, & 25.66, & 14.29, \\
& 24.32 & 27.22 & 18.41 & 26.63 & 18.73 & 13.16 & 15.09 & 24.8 \\
\hline
\end{tabular}

The mortar sample with formulation of HPCMM18_28, also has a similar behavior to the corresponding MC18 and MC28 for the onset temperatures and end temperatures of the solid-liquid phase transition.

It can therefore be inferred that the several constituents of the mortar mixes seem to have none or negligible effect on the transitions of the microencapsulated PCMs (both on the temperatures and on the enthalpies). The observed differences can probably be justified by potential inaccuracies caused by the algorithm used to estimate onset and end temperatures, or by possible inhomogeneity within the samples.

For the sample of SPCMM24, a latent heat value of $29.76 \mathrm{~kJ} / \mathrm{kg}$ was obtained for the melting phase transition of the PCM which is, approximately, $18.35 \%$ of the corresponding values obtained for the independent MC24. This relation of $18.35 \%$ is consistent with the mass ratio of MC24 in the mortar SPCMM24, which is of $18.34 \%$ according to Table 2, thus pointing to the possibility of predicting enthalpy of mortars that incorporate PCM.

Fig. 10 represents the DSC curves of the SPCMM24 and HPCMM18_28 for heating and cooling processes. In specific regard to HPCMM18_28, two main peak points are identifiable in the cooling process curve (Fig. 10b) of the DSC. The first peak point corresponds to phase change transition of MC18 (labeled as $\mathrm{X}$ in Fig. 10b). The second peak corresponds to the MC28 phase change transition (peak_MC28 labeled in Fig. 10b). The smaller peak points were omitted for the calculation of the enthalpy values for both heating and cooling processes for all samples.

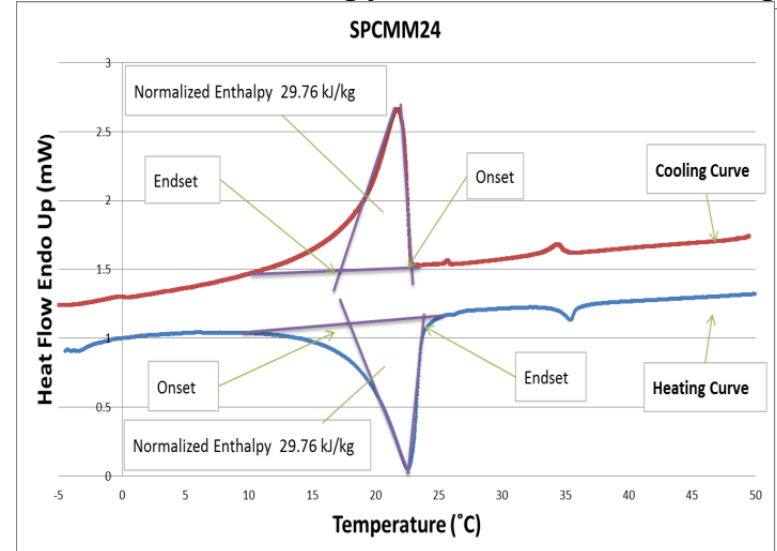

a)

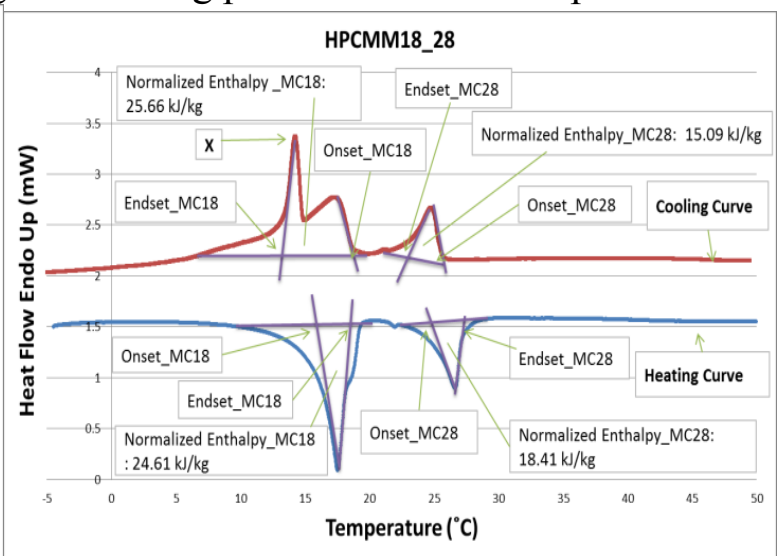

b)

Fig. 10. (a) DSC result of sample SPCMM24; (b) DSC results of HPCMM18_28 sample for heating/cooling processes. 


\section{Conclusion}

Based on these results, it can be concluded that the use of PCM microcapsules in lime-gypsum mortars can be seen as a viable solution for applications in the construction industry. However, it was also verified that the use of different phase change materials microcapsules provides different characteristics in the different mortars, which is related to the type of polymer used for the construction of the wall of the microcapsules and also to their size.

According to the research made with the different DSC tests the following main conclusions can be drawn: (1) the mixing of two PCMs has a similar behaviour to the superposition of effects of independent PCMs and therefore, it can be inferred that they have not interacted with each other; (2) DSC testing of different samples shows that both plain microencapsulated paraffin samples (PCM) and plaster mortars containing microencapsulated PCM (SPCMM24 and HPCMM18_28) exhibit hysteretic behaviour of the phase change temperature in regard to heating/cooling cycles; (3) enthalpy is linearly proportional to the mass fraction of PCM in the mortar sample as compared to the behaviour of plain PCM samples.

\section{References}

[1] M. Diamanti, M. Ormellese, M. Pedeferri, Characterization of photocatalytic and superhydrophilic properties of mortars containing titanium dioxide, Cement and Concrete Research. 38 (2008) 1349-1353.

[2] Y. Zhang, G. Zhou, K. Lin, K. Zhang, H. Di, Application of latent heat thermal energy storage in buildings: State-of-the-art and outlook, Build Environ. 42 (2007) 2197-2209.

[3] B. Zalba, J. Marín, L. Cabeza, H. Mehling, Review on thermal energy storage with phase change: materials, heat transfer analysis and applications, Appl Therm Eng. 23 (2003) 251-283.

[4] M. Schmid, in Heat management with Phase Change Material. Seminário Argamassas Funcionais para uma Construção Sustentável, Aveiro (2011).

[5] L. Cabeza, A. Castell, C. Barreneche, A. Gracia, A. Fernández, Materials used as PCM in thermal energy storage in buildings: A review, Renew Sustainable Energy Reviews. 15 (2011) 1675-1695.

[6] V. Tyagi, S. Kaushik, S.Tyagi, T.Akiyama, Development of phase change materials based microencapsulated technology for buildings: A review, Renew Sustainable Energy Reviews. 15 (2011) 1373-1391.

[7] E. Halawa, F. Bruno, W. Saman, Numerical analysis of a PCM thermal storage system with varying wall temperature, Energy Conversion and Management. 46 (2005) 2592-2604.

[8] Z. Liu, C. Ma, Numerical analysis of melting with constant heat flux heating in a thermal energy storage system, Energy Conversion and Management. 43 (2002) 2521-2538.

[9] A. Sharma, V. Tyagi, C. Chen, D. Buddhi, Review on thermal energy storage with phase change materials and applications, Renew Sustainable Energy Reviews. 13 (2009) 318-345.

[10]C. Castellon, E. Gunther, H. Mehling, Determination of the enthalpy of PCM as a function of temperature using a heat-flux DSC, A study of different measurement procedures and their accuracy, Journal of Energy Research. 32 (2008) 1258-1265.

[11]E. Gunther, E.Hiebler,H Mehling, Enthalpy of phase change materials as a function of temperature: required accuracy and suitable measurement methods, International Journal of Thermophysics. 30 (2009) 1257-1269. 
[12] C. Barreneche, A. Solé, L. Miróa, I. Martorella, I. Fernández, L. Cabeza, Study on differential scanning calorimetry analysis with two operation modes and organic and inorganic phase change material (PCM), Thermochimica Acta. 553 (2013) 23-26.

[13]E. Günther, S. Hiebler,H. Mehling, Determination of the heat storage capacity of PCM and PCM-objects as a function of temperature in: ECOSTOCK, international conference on thermal energy storage (2006).

[14] A. Khudhair, M. Farid, A review on energy conservation in building applications with thermal storage by latent heat using phase change materials, Energy Convers Management. 45 (2004) 263275.

[15]A. Athienitis, C. Liu, D. Hawes, D. Banu, D. Feldman, Investigation of the Thermal Performance of a Passive Solar Test-Room with Wall Latent Heat Storage, Build Environ. 32 (1997) 405-410.

[16]L. Shilei, Z. Neng, F. Guohui, Impact of Phase Change Wall Room on Indoor Thermal Environment in winter, Energy Build. 38 (2006) 18-24.

[17] K. Darkwa, P. O'Callaghan, D. Tetlow, Phase-change drywalls in a passive-solar building, Appl Energy. 83 (2006) 425-435.

[18]P. Schossig, H. Henning, S. Gschwander, T. Haussmann, Micro-encapsulated Phase Change Materials Integrated Into Construction Materials, Sol Energy Mater Sol Cells. 89 (2005) 297-306.

[19] M. Ahmad, A. Bontemps, H. Sallée, D. Quenard, Thermal Testing and Numerical Simulation of a Prototype Cell Using Light Wallboards Coupling Vacuum Isolation Panels and Phase Change Material, Energy Build. 38 (2006) 673-681.

[20]K. Lin, Y. Zhang, X. Xu, H. Di, R. Yang, P. Qin, Experimental Study of Under-Floor Electric Heating System with Shape-Stabilized PCM Plates, Energy Build. 37 (2005) 215-220.

[21]A. Entrop, H. Brouwers, A. Reinders, Experimental research on the use of micro-encapsulated Phase Change Materials to store solar energy in concrete floors and to save energy in Dutch houses, Solar Energy. 85 (2011) 1007-1020.

[22] X. Jin, X. Zhang, Thermal analysis of a double layer phase change material floor, Applied Thermal Engineering, Appl Therm Eng. 31 (2011) 1576-1581.

[23] M. Koschenz, B. Lehmann, Development of a Thermally Activated Ceiling Panel with PCM for Application in Lightweight and Retrofitted Buildings, Energy Build. 36 (2004) 567-578.

[24] A. Pasupathy, L. Athanasius, R. Velraj, R. Seeniraj, Experimental investigation and numerical simulation analysis on the thermal performance of a building roof incorporating phase change material (PCM) for thermal management, Appl Therm Eng. 28 (2008) 556-565. 


\section{Sustainable Construction Materials}

10.4028/www.scientific.net/KEM.634

\section{Mortars with Phase Change Materials: Contribute to Sustainable Construction} 10.4028/www.scientific.net/KEM.634.3

\section{DOI References}

[1] M. Diamanti, M. Ormellese, M. Pedeferri, Characterization of photocatalytic and superhydrophilic properties of mortars containing titanium dioxide, Cement and Concrete Research. 38 (2008) 1349-1353. http://dx.doi.org/10.1016/j.cemconres.2008.07.003

[2] Y. Zhang, G. Zhou, K. Lin, K. Zhang, H. Di, Application of latent heat thermal energy storage in buildings: State-of-the-art and outlook, Build Environ. 42 (2007) 2197-2209.

http://dx.doi.org/10.1016/j.buildenv.2006.07.023

[5] L. Cabeza, A. Castell, C. Barreneche, A. Gracia, A. Fernández, Materials used as PCM in thermal energy storage in buildings: A review, Renew Sustainable Energy Reviews. 15 (2011) 1675-1695. http://dx.doi.org/10.1016/j.rser.2010.11.018

[6] V. Tyagi, S. Kaushik, S. Tyagi, T. Akiyama, Development of phase change materials based microencapsulated technology for buildings: A review, Renew Sustainable Energy Reviews. 15 (2011) 13731391.

http://dx.doi.org/10.1016/j.rser.2010.10.006

[7] E. Halawa, F. Bruno, W. Saman, Numerical analysis of a PCM thermal storage system with varying wall temperature, Energy Conversion and Management. 46 (2005) 2592-2604.

http://dx.doi.org/10.1016/j.enconman.2004.11.003

[8] Z. Liu, C. Ma, Numerical analysis of melting with constant heat flux heating in a thermal energy storage system, Energy Conversion and Management. 43 (2002) 2521-2538.

http://dx.doi.org/10.1016/S0196-8904(01)00190-X

[9] A. Sharma, V. Tyagi, C. Chen, D. Buddhi, Review on thermal energy storage with phase change materials and applications, Renew Sustainable Energy Reviews. 13 (2009) 318-345.

http://dx.doi.org/10.1016/j.rser.2007.10.005

[10] C. Castellon, E. Gunther, H. Mehling, Determination of the enthalpy of PCM as a function of temperature using a heat-flux DSC, A study of different measurement procedures and their accuracy, Journal of Energy Research. 32 (2008) 1258-1265.

http://dx.doi.org/10.1002/er.1443

[12] C. Barreneche, A. Solé, L. Miróa, I. Martorella, I. Fernández, L. Cabeza, Study on differential scanning calorimetry analysis with two operation modes and organic and inorganic phase change material (PCM), Thermochimica Acta. 553 (2013) 23-26. http://dx.doi.org/10.1016/j.tca.2012.11.027

[14] A. Khudhair, M. Farid, A review on energy conservation in building applications with thermal storage by latent heat using phase change materials, Energy Convers Management. 45 (2004) 263275. http://dx.doi.org/10.1016/S0196-8904(03)00131-6 [15] A. Athienitis, C. Liu, D. Hawes, D. Banu, D. Feldman, Investigation of the Thermal Performance of a Passive Solar Test-Room with Wall Latent Heat Storage, Build Environ. 32 (1997) 405-410. http://dx.doi.org/10.1016/S0360-1323(97)00009-7

[16] L. Shilei, Z. Neng, F. Guohui, Impact of Phase Change Wall Room on Indoor Thermal Environment in winter, Energy Build. 38 (2006) 18-24. 
http://dx.doi.org/10.1016/j.enbuild.2005.02.007

[17] K. Darkwa, P. O'Callaghan, D. Tetlow, Phase-change drywalls in a passive-solar building, Appl Energy. 83 (2006) 425-435.

http://dx.doi.org/10.1016/j.apenergy.2005.05.001

[18] P. Schossig, H. Henning, S. Gschwander, T. Haussmann, Micro-encapsulated Phase Change Materials Integrated Into Construction Materials, Sol Energy Mater Sol Cells. 89 (2005) 297-306.

http://dx.doi.org/10.1016/j.solmat.2005.01.017

[19] M. Ahmad, A. Bontemps, H. Sallée, D. Quenard, Thermal Testing and Numerical Simulation of a

Prototype Cell Using Light Wallboards Coupling Vacuum Isolation Panels and Phase Change Material, Energy Build. 38 (2006) 673-681.

http://dx.doi.org/10.1016/j.enbuild.2005.11.002

[20] K. Lin, Y. Zhang, X. Xu, H. Di, R. Yang, P. Qin, Experimental Study of Under-Floor Electric Heating System with Shape-Stabilized PCM Plates, Energy Build. 37 (2005) 215-220.

http://dx.doi.org/10.1016/j.enbuild.2004.06.017

[21] A. Entrop, H. Brouwers, A. Reinders, Experimental research on the use of micro-encapsulated Phase Change Materials to store solar energy in concrete floors and to save energy in Dutch houses, Solar Energy. 85 (2011) 1007-1020.

http://dx.doi.org/10.1016/j.solener.2011.02.017

[22] X. Jin, X. Zhang, Thermal analysis of a double layer phase change material floor, Applied Thermal Engineering, Appl Therm Eng. 31 (2011) 1576-1581.

http://dx.doi.org/10.1016/j.applthermaleng.2011.01.023

[23] M. Koschenz, B. Lehmann, Development of a Thermally Activated Ceiling Panel with PCM for Application in Lightweight and Retrofitted Buildings, Energy Build. 36 (2004) 567-578.

http://dx.doi.org/10.1016/j.enbuild.2004.01.029 